\title{
Cytological endometritis in dairy cows: a preliminary study
}

\author{
A.A. A. Zyada1, M.M. Hussein ${ }^{2}$, S.M. Abd-Allah², A.A.Y. Khalil', R.L. Abdel Aziz' \\ ${ }^{1}$ Veterinarian at Fayoum Governorate, Egypt. \\ ${ }^{2}$ Department of Theriogenology, Faculty of Veterinary Medicine, Beni-Suef University, Egypt
} Received: 07 August 2019/ Accepted 18 Sept. 2019/Publication date: 25 Oct. 2019

\begin{abstract}
The current study was carried out as a preliminary study to determine the incidence of cytological endometritis (CE) and to investigate its effects on pregnancy in dairy cows. Forty nine dairy cows belonging to two farms were included in the study. Cows were enrolled between 28-42 days in milk (DIM) in farm $1(n=25)$, while in farm $2(n=24)$, some cows $(n=8)$ were enrolled at $D I M>200$. Cows were fed three times daily on totally mixed ration (TMR) and were milked three times using automatic parlours. Uterine samples were obtained from examined cows and were stained with Diff-Quick stain to determine the percentage of polymorphonuclear cells (PMN). A PMN\% greater than 18 was taken as indicator of CE. Data pertaining to parity, breed, milk production, conception were obtained from automatic records. Results showed numerically higher incidence of CE in Holstein cows and in low producing cows. In addition, postpartum problems during the first ten days as retained placenta and metritis increased the incidence of $\mathrm{CE}$ in examined cows. Furthermore, $\mathrm{CE}$ was associated with numerically higher figures of culling among cows and cows with $\mathrm{CE}$ achieved lower pregnancy rates, compared to those without CE.
\end{abstract}

Keywords: Cytological endometritis, Polymorhponuclear cells, incidence, pregnancy, dairy cattle

\section{Introduction}

Dairy cows suffering from metabolic stress after calving, were accompanied by dramatic changes in metabolic hormones and nutrients, including reduced glucose, glutamine and insulin-like growth factor 1 (Chagas et al., 2007; Kerestes et al., 2009). The resulting negative energy balance may impair the inflammatory response and clearance of bacteria from the endometrium, leading to chronic uterine disease (Esposito et al., 2014).

According to Kasimanickam et al. (2004), subclinical endometritis can be defined as the existence of liquefied material in the uterine cavity at 31 days post-delivery or later with a cervical diameter $5-7 \mathrm{~cm}$ and a uterine diameter $5-8 \mathrm{~cm}$. Based on immunological evidence, Subclinical endometritis is defined as existence of $>18 \%$ polymorph nucleotide (PMN) cells in uterine cytology samples collected 21-33 days post-delivery, or $>10 \%$ PMNs in samples gathered at times 34-47 days postpartum without uterine discharge; nevertheless, affected cows exhibit impaired reproductive presentation(Sheldon et al., 2006).

Available literature also define subclinical endometritis as the superficial inflammation of the endometrium, without visible clinical signs, but significantly impairing reproductive performances (Sheldon et al., 2006; Kasimanickam et al., 2004; Gilbert et al., 2005).

Definitely, histopathology is considered as the gold standard to diagnose endometritis in mares (Van Camp, 1988 ; Snider et al., 2011).

Meanwhile, in cattle, endometrial biopsy is rarely used since it is considered to be timeconsuming, expensive and potentially detrimental for future fertility (Sheldon et al., 2006; Sheldon et al., 2004).

Other researchers diagnosed cytological endometritis (CE) using ultrasonography, the presence of fluid in the uterus between 20 to 47 days postpartum has been shown to be associated with a significant reduction in the relative pregnancy rate in comparison to cows that appeared "clean" at examination (Kasimanickam et al., 2004; Gobikrushanth et al., 2016; Šavc et al., 2016). However, the

Corresponding Author: A.A. A. Zyada, Veterinarian at Fayoum Governorate, Egypt.

E-mail: ali.zyada99@yahoo.com 
matching results between ultrasound and endometrial cytology is low. The ultrasound and cytology measure two different representations of SCE.

Endometrial cytology is the most used technique to diagnose SCE in cattle in both field and research setups (Dubuc et al., 2010; De Boer et al., 2014). The measurement of the proportion of PMNs in cytology slides is the mark for SCE diagnosis, to the point that some authors refer bovine SCE to as "cytological endometritis" (CE) (De Boer et al., 2014)

The present work aimed to clarify the variation in the incidence of $\mathrm{CE}$ among dairy cows based on differences in milk production and breed of cows. Additionally, the incidence of CE in normal cows and those suffering from infertility problems during the first ten days after calving has been studied. Moreover, we aimed to determine if there are any negative impacts of $\mathrm{CE}$ on future performance of cows and culling rates.

\section{Material and methods}

\section{Animals, housing and management}

The study was carried out on 49 mixed parity dairy cows belonging to two dairy herds in Western and North-western Egypt.

\section{Herd one}

Twenty five lactating cows of different breeds (Holstein, Brown Swiss, and Simmental), with an age ranged from 2 to 10 years were subjected to this study from commercial dairy farm. Cows were fed total mixed ration (TMR), milked three times daily using an automatic milking parlor. The strategy of heat detection included both pedometric evaluation of increased stepping of estrous cows and visual detection of standing heat. The visual detection was carried out three times daily for 30 minutes each by experienced farm workers. All examined cows appeared normal with no signs of clinical endometritis. Cows between 28 to 42 days postpartum were identified by herd records.

\section{Herd two}

Twenty four lactating Holstein cows with age ranged from 3-8 year old. Eight cows had days in milk more than 200 days and 16 cows had days in milk 22- 24 days, Cows were housed in an open yard system, fed TMR, milked three times daily using an automatic milking parlour. Heat detection was carried out using continuous visual observation of estrus by trained farm personnel. The post-partum cows were apparently healthy and free from Purulent Vaginal Discharge. Data recorded included (days in milk, age, parity, body condition score and milk production).

\section{Sampling and endometrial cytology}

The cellular material was collected using a cytobrush consisted of short brush $1 \mathrm{~cm}$ in length attached to a rod and covered by plastic sleeve. After careful restraint of the animal, the vulva was cleaned by paper towel to remove fecal materials and any contaminants. The brush covered by the plastic sleeve was inserted into the vagina through the a parted vulvar lips, firstly oblique dorsally then the brush was turned horizontally through the vagina to the external cervical os, then the plastic sleeve was retracted backward and the rod with its brush was introduced forward to reach endometrial mucosa of uterine body where the rod of brush was rotated full 360 degrees. The brush and rod were retracted into the guard and carefully removed from the reproductive tract. Finally, the cytobrush was rolled on a clean microscopic slide for routine cytology staining and assessment.

\section{Staining of cytological smears}

Cytological smears were left to air drying and stained with Rapi-Diff II stain Kit (Atom scientific, Manchester, London, UK) according to manufacturer instructions.

\section{Assessment of the cytological smears}

Cytological assessment was determined as the percent of different types of endometrial epithelial cells (type A, type B, and/or type C cells) and PMNs. Detection of percent of both endometrial epithelial cells and PMNs was based on counting of all cells in 10 microscopic fields of view (Kasimanickam et al., 2004, 2005; Prieto et al., 2012) to determine the percentage. Proportions of PMNs were based on 
(PMNs/ PMNs + endometrial cells). All slides were examined using light microscope (Leica DM 2500) with full HD camera (DFC 290 HD 12730202) at 400x magnification.

\section{Counting of different cell types}

Ten captured images per microscopic slide were subjected to image-J software (NIH, USA), different endometrial cells that involve epithelial (type A, type B, type C, and degenerated epithelial cells) and inflammatory cells (PMNs) were counted. Detection of the main percentages of each type of cells was performed.

\section{Statistical analysis}

Variation of the incidence of SCE among cows as well as conception rate was determined using chi square test. A p value less than 0.05 was considered significant.

\section{Results}

Data displayed in table 1 showed the incidence of $\mathrm{CE}$ in normal and problem cows. The incidence of $\mathrm{CE}$ was higher in problem cows accounting for $50.00 \%$ of cases. Meanwhile, the incidence of CE in normal cows was as low as $20.93 \%$. In spite of that, the difference in the incidence of CE between normal and problem cows was not significant (Chi square $=2.41, P=0.15$ ).

Table 1: Incidence of cytological endometritis in normal and affected cows

\begin{tabular}{llccccc}
\hline & & Normal cow & Affected cow & Chi square & P value \\
\hline $\begin{array}{l}\text { Number of cows } \\
\text { Number of }\end{array}$ & \multirow{2}{*}{ cows } & with & 43 & 6 & NA & NA \\
PMN\%> 18\% & & & 9 & 3 & NA & NA \\
CE (\%) & & 20.93 & 50 & 2.41 & 0.15 \\
\hline
\end{tabular}

PMN\%: Polymorphonuclear cells; CE: Cytological endometritis, NA: Not applicable

The incidence of CE according to milk yield of examined cows was represented in Table 2. Out of 18 high yielding cows, the number of high producing cows $(>10000 \mathrm{~kg}$ milk/305 days) with CE was 3 yielding an incidence rate of $16.67 \%$. The incidence of $\mathrm{CE}$ was $26.92 \%(7 / 26)$ in cows producing less than $10000 \mathrm{Kg}$ milk/305 days. But this variation also did not achieve a statistical significance (Chi square $=1.13, P=0.24)$.

Table 2: Incidence of cytological endometritis according to milk production

\begin{tabular}{lccc}
\hline & Number of cows & $\begin{array}{c}\text { Number of cows with } \\
\text { PMNC } \mathbf{~ 1 8 \%}\end{array}$ & Incidence of CE (\%) \\
\hline More than $\mathbf{1 0 0 0 0 ~ K g}$ & 18 & 3 & 16.67 \\
$<\mathbf{1 0 0 0 0 ~ K g}$ & 26 & 7 & 26.92 \\
Chi square & & 1.13 & \\
P value & & 0.24 & \\
\hline
\end{tabular}

CE: Cytological endometritis; PMN: Polymorphonuclear cells

Regarding the incidence of CE in the different breeds of cows in the current study, breed did not have significant (Chi square $=1.82, \mathrm{P}=0.17$ ) effects on $\mathrm{CE}$ in dairy cows. A numerically higher percentage of Holstein cows (11/37, 29.73\%) showed CE, meanwhile, Brown Swiss cows showed an incidence of $8.33 \%(1 / 12)$, as clarified in Table 3 .

Table 3: Incidence of cytological endometritis in different dairy breeds

\begin{tabular}{lccc} 
& Number of cows & $\begin{array}{c}\text { Number of cows with } \\
\text { PMNC }>18 \%\end{array}$ & Incidence of CE (\%) \\
\hline Holstein & 37 & 11 & 29.73 \\
Brown Swiss & 12 & 1 & 8.33 \\
Chi square & NA & NA & 1.82 \\
P value & NA & NA & 0.17 \\
\hline
\end{tabular}

CE: Cytological endometritis; PMN: Polymorphonuclear cells 
The effect of CE on culling rate in dairy cows is illustrated in Table 4. Culled cows were older $(4.93 \pm 0.37$ vs $3.71 \pm 0.29$ years, respectively), $(F=6.11, P=0.02)$ than normal cows. In addition, PMNC\% tended $(F=3.63, P=0.06)$ to be higher in culled cows $(20.45 \pm 5.40 \%)$, when compared to normal cows $(7.45 \pm 3.16 \%)$. Regarding the proportion of cows diagnosed with $\mathrm{CE}$, a higher proportion of culled cows $(28.13 \%)$ was diagnosed with CE than that of normal cows $(17.65 \%)$, yet the difference between the two groups was not significant $(F=0.66, P=0.33)$.

According to Fig.1, cows suffering from $\mathrm{CE}$ achieved lower pregnancy rate when compared to those without CE. Nevertheless, the difference was not significant.

Table 4: Culling of cows with cytological endometritis and normal cows

\begin{tabular}{lcccc}
\hline & Culled cows & Normal cows & Chi square & P value \\
\hline Age & $4.93 \pm 0.37$ & $3.71 \pm 0.29$ & 6.11 & 0.02 \\
PMNC\% & $20.45 \pm 5.40$ & $7.45 \pm 3.16$ & 3.63 & 0.06 \\
\% with CE & $9 / 32(28.13)$ & $3 / 17(17.65)$ & 0.66 & 0.33 \\
\hline
\end{tabular}

CE: Cytological endometritis; PMN: Polymorphonuclear cells

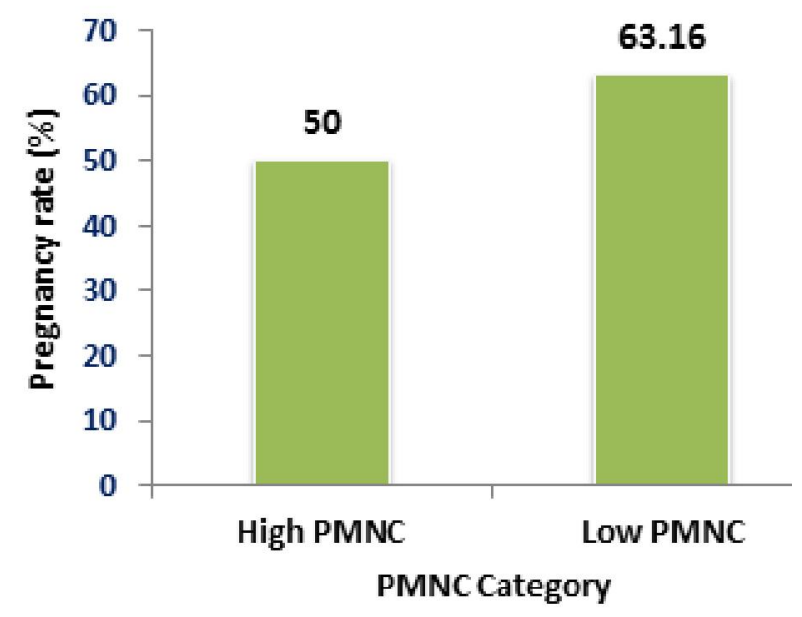

Fig. 1: Pregnancy rate of cows with low $(<18 \%)$ and high $>18 \%)$ percentage of polymorhonuclear cells

\section{Discussion}

The present work aimed to clarify the variation in the incidence of $\mathrm{CE}$ among dairy cows based on differences in milk production and breed of cows. Additionally, the incidence of CE in normal cows and those suffering from infertility problems during the first ten days after calving has been studied. Moreover, we aimed to determine if there are any negative impacts of $\mathrm{CE}$ on future performance of cows and culling rates.

In the current investigation, although not significant, problem cows had higher incidence of CE than did their normal herd-mates. Similarly, Lee et al. (2018) mentioned that diseases like retained placenta, and septic metritis increase the incidence of CE due to creating and establishing favorable conditions for microbial growth inside the uterus. In our study, the low number of cows included in the study might have influenced the statistical significance.

Interestingly, results from the current work revealed that high producing cows had numerically lower incidence of $\mathrm{CE}$, when compared to lower producing cows. It is likely that low producing cows might have suffered from subclinical mastitis which is linked to the development of CE. Subclinical mastitis can directly and significantly influence the prevalence of subclinical endometritis at 30 days postpartum and 60 days postpartum with ORs of 4.5 and 3.6, respectively (Bacha and Regassa, 2010). Even if the odds ratio of mastitis for the prevalence of clinical endometritis is higher than 1, sometimes the relationships are not statistically significant (Potter et al., 2010).

The incidence of CE was higher in Holstein cows than in Brown Swiss herd-mates in the present investigation. Holstein cows are more sensitive to production and routine daily activity stressors than Brown swiss cows and this might have made them more susceptible to the development of SCE. 
Culled cows scored numerically higher proportions of PMN, compared to cows that stayed in the herd. Moreover, cows with higher PMN achieved lower pregnancy rates than did cows with low PMN. This finding substantiates the negative influences of $\mathrm{CE}$ on reproductive performance and longevity of dairy cows inside the herd.

The decreases in reproductive performance (low probability of conception following the first insemination, more AIs required per conception, and lower chance of conception by 200 days postpartum) observed in cows with CEM in the present study are comparable to the results of several previous studies (Kasimanickam et al., 2004; Gilbert et al., 2005; Barlund et al., 2008; Ahmadi et al., 2016; Lee et al., 2018).

\section{Conclusion}

The incidence of CE in Holstein cows is higher than in Brown Swiss herd-mates. In addition, high milk production in dairy cows was associated with lower incidence of CE. CE in dairy cows increased the culling and led to impaired reproductive performance as reflected by lowered pregnancy rates.

\section{Acknowledgment}

The authors would like to thank the owners of the dairy farms where the work has been carried out. Also we would like to acknowledge Dr. Hussein El-Said, head of veterinary sector, milkys farm for his great help.

\section{Conflict of interest}

The authors do not have any conflict of interest.

\section{References}

Ahmadi M.R., A. Kadivar and M. Vatankhah, 2016. Evaluation of polymorph nuclear (PMN) cells in cervical sample as a diagnostic technique for detection of subclinical endometritis in dairy cattle. Asian Pac J Reprod., 5, 340-344.

Bacha, B., and F.G. Regassa, 2010. Subclinical endometritis in Zebu x Friesian crossbred dairy cows: its risk factors, association with subclinical mastitis and effect on reproductive performance. Trop Anim Health Prod., 42: 397-403.

Barlund, C.S., T.D. Carruthers, C.L. Waldner and C.W. Palmer, 2008.A comparison of diagnostic techniques for postpartum endometritis in dairy cattle. Theriogenology, 69, 714-723.

Chagas L.M., J.J. Bass, D. Blache, C.R. Burke, J.K. Kay, D.R. Lindsay, M.C. Lucy, G.B. Martin, S. Meier, F.M. Rhodes, J.R. Roche, W.W. Thatcher, and R. Webb, 2007. Invited review: New perspectives on the roles of nutrition and metabolic priorities in the subfertility of high-producing dairy cows. J Dairy Sci., 90:4022-4032.

De Boer, M., S. LeBlanc, J. Dubuc, S. Meier, W. Heuwieser and S. Arlt, 2014. Invited review: systematic review of diagnostic tests for reproductive-tract infection and inflammation in dairy cows. J. Dairy. Sci., 97: 3983-99.

Dubuc, J., T.F. Duffield, K.E. Leslie, J.S. Walton, and S.J. LeBlanc, 2010. Definitions and diagnosis of postpartum endometritis in dairy cows. J. Dairy Sci., 93:5225-33.

Esposito, G., P.C. Irons, E.C. Webb and A. Chapwanya, 2014. Interactions between negative energy balance, metabolic diseases, uterine health and immune response in transition dairy cows. Anim Reprod Sci., 144:60-71.

Gilbert, R.O., S.T. Shin, C.L. Guard, H.N. Erb, and M. Frajblat, 2005. Prevalence of endometritis and its effects on reproductive performance of dairy cows. Theriogenology, 64, 1879-1888.

Gobikrushanth, M., R. Salehi, D. Ambrose, and M. Colazo, 2016. Categorization of endometritis and its association with ovarian follicular growth and ovulation, reproductive performance, dry matter intake, and milk yield in dairy cattle. Theriogenology, 86:1842-1849.

Kasimanickam, R., T.F. Duffield, R.A Foster, C.J. Gartley, K.E. Leslie, J.S Walton, and W.H. Johnson, 2004. Endometrial cytology and ultrasonography for the detection of subclinical endometritis in postpartum dairy cows. Theriogenology, 62: 9-23. 
Kerestes, M., V. Faigl, M. Kulcsar, O. Balogh, J. Foldi, H. Febel, Y. Chilliard, and G. Huszenicza, 2009. Periparturient insulin secretion and whole-body insulin responsiveness in dairy cows showing various forms of ketone pattern with or without puerperal metritis. Domest Anim Endocrinol., 37:250-261.

Lee, S.C., J.K. Jeong, I.S. Choi, H.G. Kang, Y.H. Jung, S.B. Park, I.H. Kim, 2018. Cytological endometritis in dairy cows: diagnostic threshold, risk factors, and impact on reproductive performance. J. Vet. Sci., 19(2): 301-308.

Potter, T.J., J. Guitian, J. Fishwick, P.J. Gordon and I.M. Sheldon, 2010. Risk factors for clinical endometritis in postpartum dairy cattle. Theriogenology, 74: 127-134.

Šavc, M., M. Duane, L.E. O'Grady, J.R. Somers, and. M.E. Beltman, 2016. Uterine disease and its effect on subsequent reproductive performance of dairy cattle: a comparison of two cow-side diagnostic methods. Theriogenology, 86:1983-1988.

Sheldon, I. M., D. E. Noakes, A. N. Rycroft, and H. Dobson, 2004. Effect of postpartum manual examination of the vagina on uterine bacterial contamination in cows. Vet Rec 151:531-534.

Sheldon, I.M., G.S. Lewis, S. LeBlanc, R.O. Gilbert, 2006. Defining postpartum uterine disease in cattle. Theriogenology, 65:1516-1530.

Snider, T.A., C. Sepoy, and G.R. Holyoak, 2011. Equine endometrial biopsy reviewed: observation, interpretation, and application of histopathologic data. Theriogenology, 75:1567-81.

Van Camp, S.D., 1988. Endometrial biopsy of the mare. A review and update. Vet. Clin. North. Am. Equine. Pract., 4:229-45. 